\title{
A Review on Stab and Spike Resistance Performance of Shear Thickening Fluids (STF) Impregnated Fabrics
}

\author{
Yusuf Salim ${ }^{1}$, M.Y. Yahya ${ }^{2}$, H.A. Israr ${ }^{3}$ and R. Mohamed ${ }^{4}$
}

\begin{abstract}
This paper provides a brief review on relevant literature related to shear thickening fluids (STF) impregnated fabrics on stab and spike resistance performance. Soft body armours consist of multiple layers of high performance fabric to stop stab and spike threats. To reduce the number of fabric layers on soft body armours, STF has been introduced. STF transforms from liquid state to a solidlike state under applied stress and return to its original state after stress is removed. Hence, several studies were conducted to enhance the stab and spike resistance of fabrics by exploiting STF unique properties. The performance of STF-fabric that affected by several factors, such as fibre properties, fabric architectures, STF rheological properties (particles size, shape and solid volume fraction), STF synthesis and impregnation process will be reviewed in this paper.
\end{abstract}

Keywords - Anti stabbing, body armour, impact, nanoparticles.

\section{INTRODUCTION}

$\mathrm{T}$ HE performance of body armours was measured from the ability to completely stop and dissipated energy from various kind of threats. Although body armours has been successfully prevent penetration from bullet, the impact energy from bullet were transferred to body armours and human body, resulting the user to experience injury called blunt force trauma injuries or backface signature injuries [1]. According to ballistic standard requirements of National Institute of Justice (NIJ), body armours are required to stopped a projectile from ballistic threats without penetration and backface signature depression depth should not exceed 44mm [2]. Probability of peoples getting serious injury or death are high when depression depth exceeds the standards value. Other important aspects in designing body armour are weight and flexibility. Lightweight armours reduce the carrying loads during operations and flexible armours offer agility and comfortability to user [3]. Numerous studies have been conducted to design lightweight and flexible soft body armours

Yusuf Salim ${ }^{1}$ is with Universiti Teknologi Malaysia as a postgraduate student (e-mail: yusufsalimdaud@gmail.com)

M.Y. Yahya ${ }^{2}$, is an Associate Professor in Centre for Composite, Faculty of Mechanical Engineering, Universiti Teknologi Malaysia, 81310 UTM Skudai, Johor, Malaysia (e-mail: yazid@ fkm.utm.my).

H.A. Israr ${ }^{3}$ is with Faculty of Mechanical Engineering, Universiti Teknologi Malaysia.

R. Mohamed is an Associate Professor in Faculty of Applied Sciences, Universiti Teknologi MARA (UiTM), 40450 Shah Alam, Selangor, Malaysia. but they only study the ballistic performance. Since last decades, the study on stabbing impact also gained considerable attention from researchers.

According to NIJ stab resistance of personal body armour standard body armours can be classified by two distinct protection classes, based on the threat posed. The first protection class is referred as "edged blade" class, which deal with threats from high quality knife blades. The second protection class is referred as "spike" class, which is intended to deal with improvised low quality knife and spike weapons type that commonly found in corrections environments [4]. For each protection classes, there are three protection levels from low to high based on different impact energy during testing. Edged blade style weapons such as knife has long cutting edge that able to cut the fabrics continuously during stab [5]. On the other hand, spike posed high threats due to sharp tip that can penetrate small gap between yarn to yarn in woven fabric and creating windowing effect [6].

Stab and spike resistance in soft body armours relatively proportional to the number of fabric layers used. The stab resistance is increase as the number of fabric layer increase. The major drawback of conventional body armours were less flexible and bulkier design due to lots of fabric layer [7]. Therefore, shear thickening fluids (STF) have been introduced to improve the stab and spike resistance of fabrics while maintaining the number of fabric layers. Hence, this brief review mainly interested on stab and spike resistance performance of fabrics impregnated with STF.

\section{II.SHEAR THICKENING FLUIDS (STF)}

STF composition consist of hard colloidal particles (e.g. nano silica) suspended in carrier fluid [8]. STF is a nonNewtonian fluid that exhibit shear thickening behaviour when stress applied to the fluid. STF behave as solid-like state when under applied stress due to increasing viscosity and when stress is removed, STF will return to the original liquid state [9]-[12]. In other word, this fluid behaviour can be called reversible process. Crawford et al. [13] conducted a rock drop experiment on corn start solution, which demonstrate solid like behaviour at short period of time right after rock impacted to the different solution concentration as shown on in Fig. 1. 


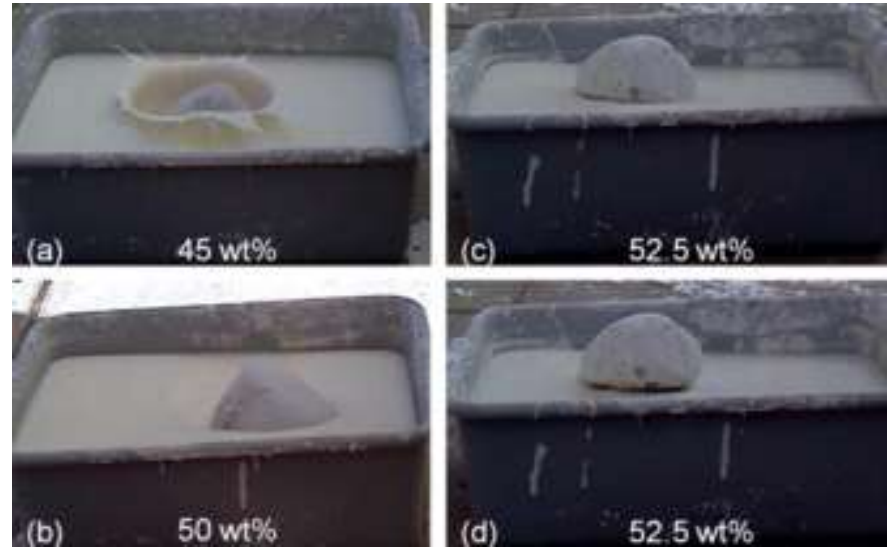

Fig. 1 Rock drop experiment on different corn starch concentration solution [13]

Initially shear thickening behaviour in fluids known as hindrance to industrial machinery due to potential of damage to equipment if not carefully controlled [14], afterward STF has been topic of interest for researchers to exploit their unique behaviours into other compromising applications, mainly in protection fields. There still no clear understanding of mechanism responsible for shear thickening behaviour, but various mechanisms theories of STF are proposed to describe shear thickening phenomena. Among these proposed theories, Hydrocluster widely accepted, this theory stated the viscosity of concentrated colloidal fluids increase dramatically due to formation of aggregates particles and jammed the fluid flow [15] as shown in Fig. 2 and these theory are supported with rheological, rheo-optics and flow-SANS experiments [16], [17]. Hydrocluster can provided tools to predict the onset of shear thickening, but it unable to explain the orders of magnitude increase in viscosity during discontinuous shear thickening [18].

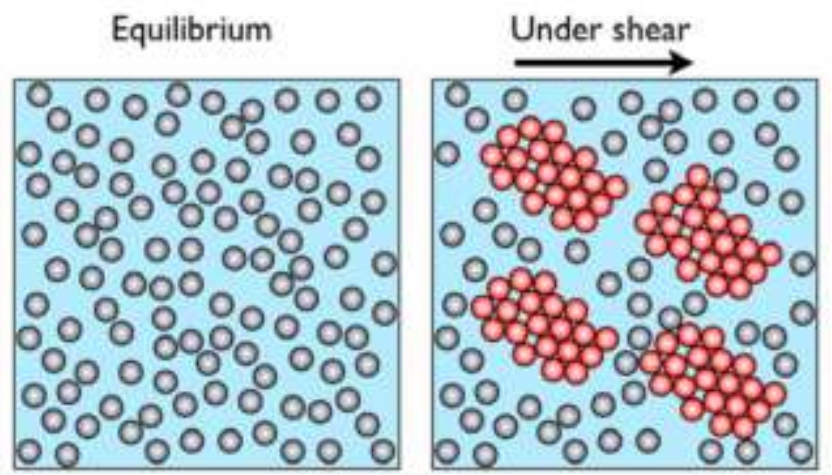

Fig. 2 Formation of aggregates particles under applied shear

There are three common methods to prepare or synthesis STF; Sonochemical method, mechanical mixing and combination of mechanical and ultrasonic mixing. Sonochemical method process used high intensity ultrasonic to deagglomeration nanoparticles to disperse into solution [19], [20]. Second method is the simplest way to synthesis STF, a known weight of silica nanoparticles and PEG are mixed with excess amount of ethanol for several hours until the solution become homogenous. Disadvantages of this method is formation of bubbles during mixing process, that could be affecting the rheological result during testing. To overcome this problem, prepared solution is needed to place inside a vacuum chamber for a period time to eliminate bubbles [21]. The last method is combination of mechanical and ultrasonic technique. It can be done either doing mechanical mixing followed by irradiation by ultrasonic horn as practiced by Kordani and Vanini [22] as Fig. 3 or can be done simultaneously. Haris et al. [23] prepared STF using high shear mixer and ultrasonic cleaning bath instead using ultrasonic horn to reduce aggregation and expel air bubbles from STF solution.

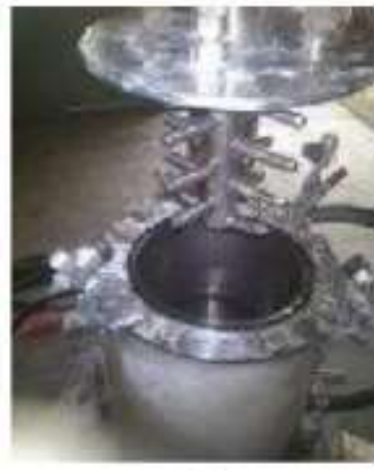

(a)

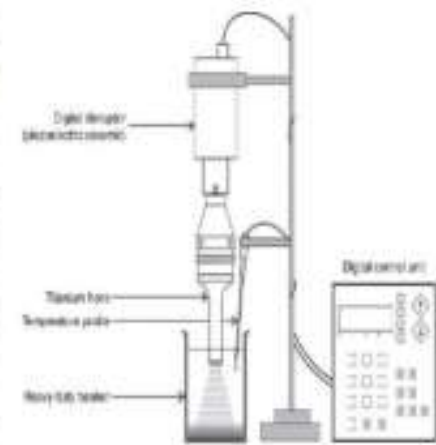

(b)
Fig. 3 Preparation of STF using (a) mechanical blender and (b) ultrasonic horn

Fabrication of STF-fabric were done using immersion or impregnation method. The prepared STF solution was diluted with ethanol for certain ratio and mixed homogenously. Ethanol was used to reduce the surface tension to make the impregnation process become easier [24]. Fabric fibres then immersed into bath for certain period and then squeeze using mandrel to remove the excess diluted STF. Final step to fabricated STF-fabric is to remove ethanol from STF and fabric using oven to evaporate the ethanol, leaving STF only on the fabric. Distribution of colloidal particles in fabric fibres can be seen through Scanning Electron Microscope (SEM) as shown in Fig. 4.

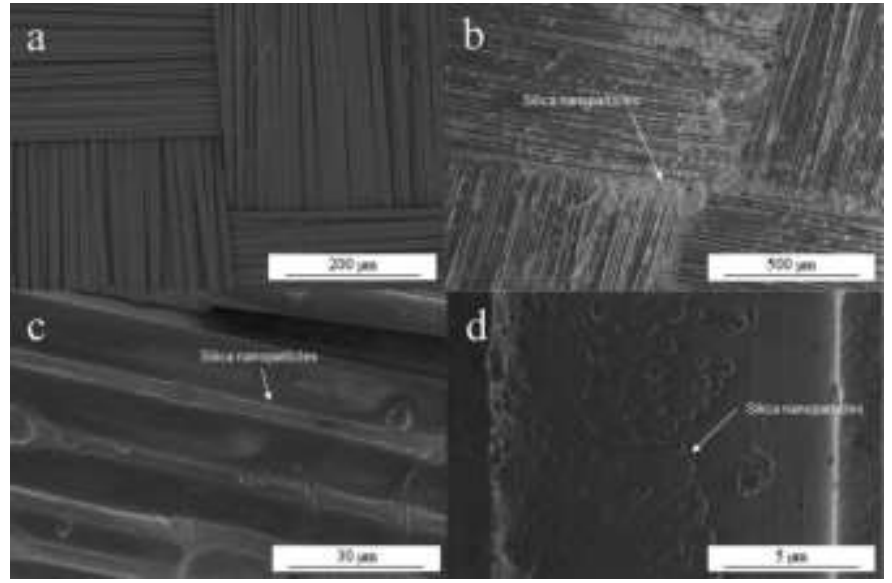

Fig. 4 SEM of Kevlar fabric (a)without STF, (b) with STF, (c)x1500 magnification of STF-Kevlar and (d) X8000 magnification [8] 


\section{STF IMPREGNATED FABRICS}

Various kind of textile fabric materials were impregnated with STF to enhance their stab and spike resistance by researcher as shown in Table 1. Xu et al. [25] studied stab resistance of Twaron woven fabric impregnated with shear thickening fluid. In their research, rheological properties of STF show that shear thickening behaviour onset at shear rate values between $2 \mathrm{~s}^{-1}$ and $70 \mathrm{~s}^{-1}$ depending on the particle size and solid volume fraction. Meanwhile, shear rate for stabbing impact calculated using (1), to be about $1500 \mathrm{~s}-1$, and this was sufficient to trigger the shear thickening behaviour of the STF. In other word, shear rate of STF required to exhibit shear thickening behaviour are less than shear rate during stabbing impact, therefore STF expected to adequately to start transition from liquid state to solid-like state as soon as impactor comes in contact with target fabric.

$$
S_{S t a b}=v / d
$$

Equation (1) represent $S_{\text {stab }}$ as shear rate for stabbing impact, where $v$ is the impact velocity and $d$ is the thickness of the impactor knife.

TABLE I

STF COMPOSITION AND FABRIC MATERIALS USED BY RESEARCHER TO STUDY STAB RESISTANCE OF STF IMPREGNATED FABRIC

\begin{tabular}{|c|c|c|c|}
\hline Colloidal Particles & Carrier Fluids & $\begin{array}{c}\text { Fabric } \\
\text { Materials }\end{array}$ & References \\
\hline $\begin{array}{l}12 \mathrm{~nm} \text { and } 650 \mathrm{nn} \\
\text { silica nanoparticles }\end{array}$ & $\begin{array}{l}\text { Polyethylene } \\
\text { Glycol (PEG) }\end{array}$ & $\begin{array}{l}\text { Plain woven } \\
\text { Twaron fabric }\end{array}$ & [25] \\
\hline $\begin{array}{l}\text { 12nm fumed silica } \\
\text { and Multi-walled } \\
\text { carbon nanotubes } \\
\text { (MWNTs) }\end{array}$ & $\begin{array}{l}\text { Polyethylene } \\
\text { Glycol (PEG) }\end{array}$ & $\begin{array}{l}\text { High modulus } \\
\text { polypropylene } \\
\text { (HMPP) fabric }\end{array}$ & [26] \\
\hline $\begin{array}{l}\text { 12nm fumed silica } \\
\text { and nano-clay }\end{array}$ & $\begin{array}{l}\text { Polyethylene } \\
\text { Glycol (PEG) }\end{array}$ & Glass fabric & [27] \\
\hline $\begin{array}{l}\text { 446nm silica } \\
\text { particles }\end{array}$ & $\begin{array}{l}\text { Ethylene Glycol } \\
\text { (EG) }\end{array}$ & $\begin{array}{l}\text { Plain woven } \\
\text { Kevlar fabric }\end{array}$ & [28] \\
\hline 40nm fumed silica & $\begin{array}{c}\text { Polyethylene } \\
\text { Glycol (PEG) \& } \\
\text { Ethylene Glycol } \\
\text { (EG) }\end{array}$ & Twaron fabric & [29] \\
\hline
\end{tabular}

Previous work done by $\mathrm{Yu}$ et al. [30] on stab performance of STF impregnated with glass fabrics found that performance of these fabrics can be improved significantly with present of STF. In their study, neat fabric and STF impregnated fabric (STF-fabric) were tested using quasi-static stab test. In single ply fabric, they found that the force required to fully penetrated the STF-fabric is $80 \%$ higher than neat glass fabric as illustrated in Fig. 5. Since STF composed of colloidal particles suspended in carrier liquid, Tan et al. [12] investigated the response of ballistic impact due to STF-fabric, water-fabric (water impregnated fabric where water as carrier liquid, dried silica-fabric (silica as colloidal particle with absent of carrier liquid) and neat fabric. In their research, they found that two ply of STF-fabric has $31 \%$ higher ballistic limit than neat fabric. At the same time, dried silica-fabric only gives $12.6 \%$ increase in ballistic limit compare to neat fabric while water-fabric recorded ballistic limits $10 \%$ lower than neat fabric. These observations show STF enhance the ballistic limit of fabric due to shear thickening behaviour and not due to the colloidal particles or carrier liquid alone.

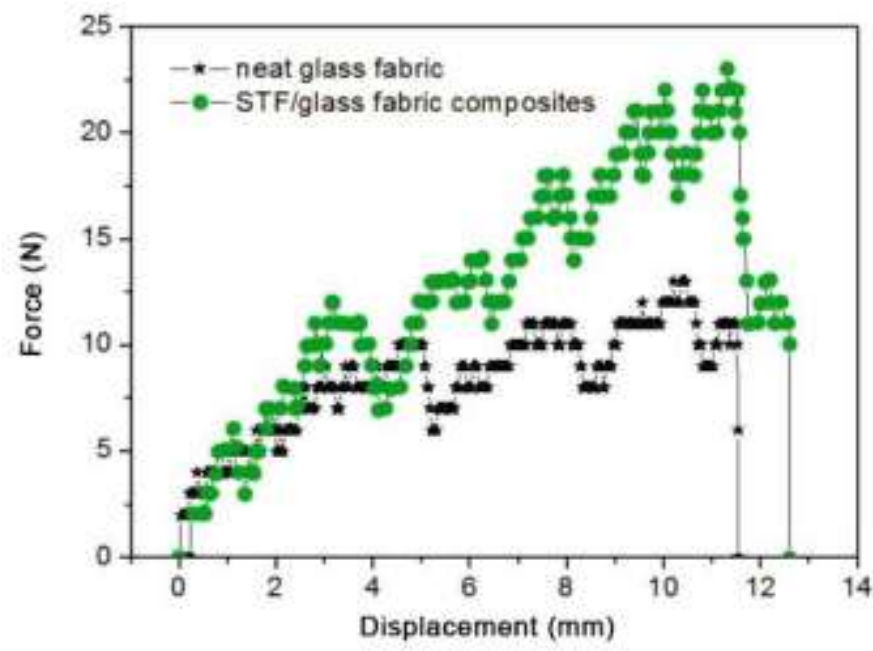

Fig. 5 Quasi-static result of neat glass fabric and STF-fabric [30]

\section{EFFECT OF STF RHEOLOGICAL PROPERTIES TO STAB AND SPIKE RESISTANCE}

There are two test experiments used to measure the performance of fabrics to stab and spike threats, drop tower testing and quasi-static testing. Drop tower testing are based on NIJ Standard 0.115.0 for stab resistance of body armour and quasi-static testing are used to describe the stabbing impact behaviour for fabrics. STF has been demonstrated the significant improvement on stab and ballistic resistance. STF show shear thickening behaviour when applied shear rates exceed the critical shear rate of fluid flow, and these rheological properties of STF are dependent upon many factors such as weight fractions, particles size and particles shape and [31]-[33].

\section{A. Weight Fraction}

Yu et al. [25] in their studies have conducted experiment to show the relationship between STF rheological properties and stab resistance of STF impregnated fabric. Their prepared three different weight fraction using same silica particle size for stabbing testing and the rheological properties result is shown on Fig. 6. STF demonstrate shear thinning behaviour at lower shear rate until reach critical shear rate, followed by increment of viscosity. In this case, at weight fraction $20 \%$, 
critical shear rate is $70 \mathrm{~s}^{-1}$ and for $30 \%$ is $8 \mathrm{~s}^{-1}$. They found that the energy absorption during drop weight and knife as impactor shows increasing the weight fraction of STF leads to increasing energy absorption during stabbing events. At $25 \%$ weight fraction, energy absorption increase $14.6 \%$ than $20 \%$ weight fraction. Meanwhile, $30 \%$ weight fraction improve the energy absorption by $23 \%$ compare to $20 \%$ weight fraction.

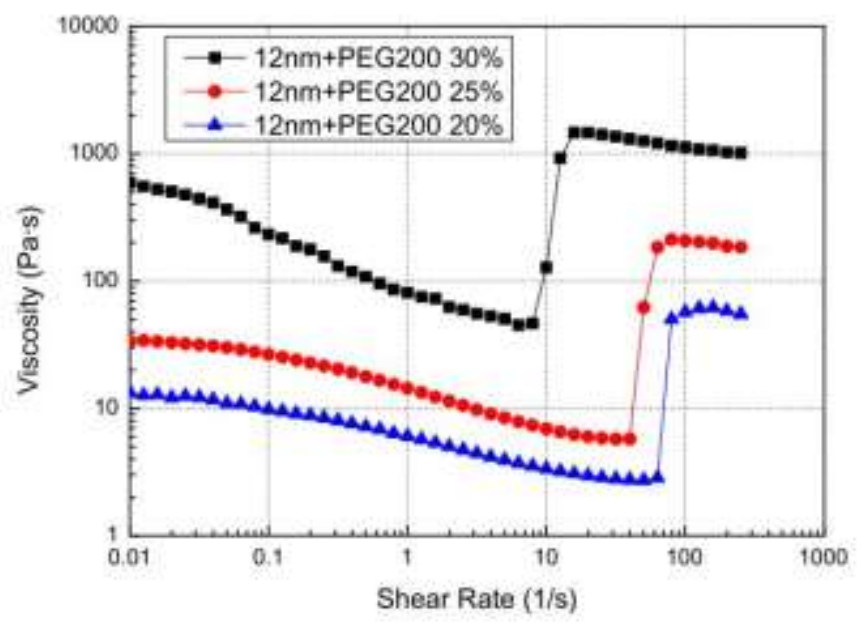

Fig. 6. Viscosity against shear rate for STF with different weight fraction [25]

\section{B. Particle Size}

Previous studies have also revealed that colloidal particle size suspended in carrier liquid also affecting shear thickening behaviour. As the particle size increases, the critical shear rate decreases as shown in Fig. 7. The critical shear rate for finer particle size can be brought down by increasing the weight fraction, but there has a limitation of percentages weight fraction can be done since the higher concentration tends to forms cluster [22]. Feng et al. [34] used two type of silica with different particle sizes $100 \mathrm{~nm}$ and 500nm for STF composition (namely STF1 and STF2) and conducting quasi-static stab test. They found the STF2-fabric (particle size is $500 \mathrm{~nm}$ ) gives highest maximum load to penetrate samples than STF1-fabric.

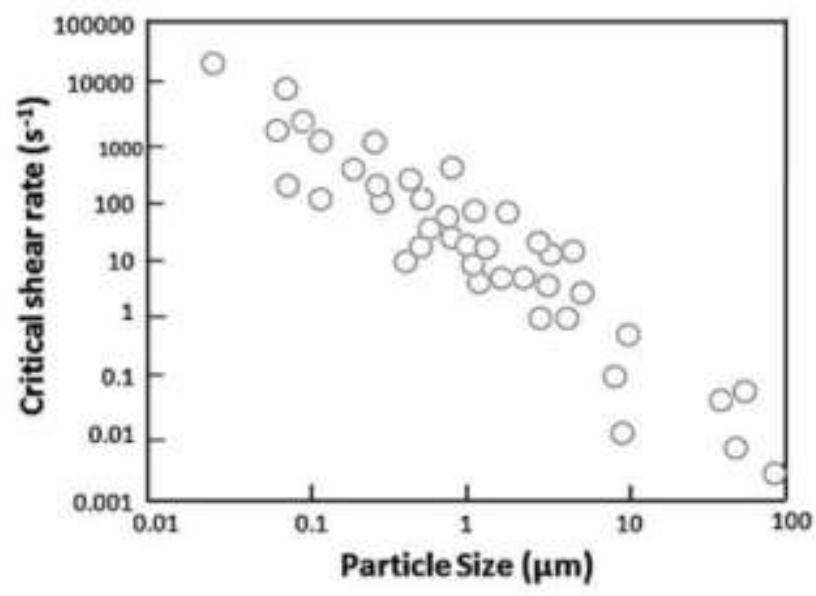

Fig. 7 Effect of particle size on critical shear rate of STF

\section{Particle Shape}

Another parameter influence the shear thickening behaviour is particle shape. Fig. 8 shows the effect of particle shape on degree of viscosity increments for colloidal suspension shape of rods, plates, grains and spheres for same weight fraction. Sharp edged particles such as rods and plates shape in the STF cause quick thickening, its believed due to particles easily to interlocking and jamming each other and restrict the fluid flow. In case of rods particles, an increase in viscosity is observed at a shear rate of $200 \mathrm{~s}^{-1}$, meanwhile for sphere particles is $300 \mathrm{~s}^{-1}$ [35].

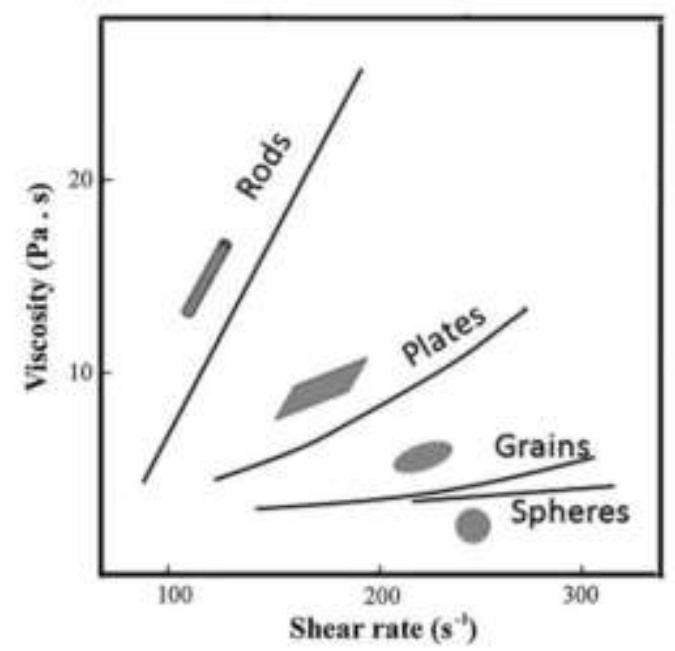

Fig. 8 Effect of particle shape on shear thickening behaviour [35]

\section{Padded Pressure}

Majumdar et al. [36] studies the impact resistance on Kevlar fabric impregnated with STF and they found that the impact energy absorption is not only influenced by rheological properties of STF, but also by the padding pressure during preparation of STF-fabric. After immersion or impregnation stage, Kevlar squeeze through two padding rollers to remove excess fluid and sets padding pressure as parameter of their studies $(0.5,1$ and 2 bar). They found the increment of padding pressure directly increased the energy absorption during impact as shown in Fig. 9. Padding pressure is believed to assist STF to impregnated deeper into yarn surface and contribute to better distribution of colloidal particles in fabrics. 


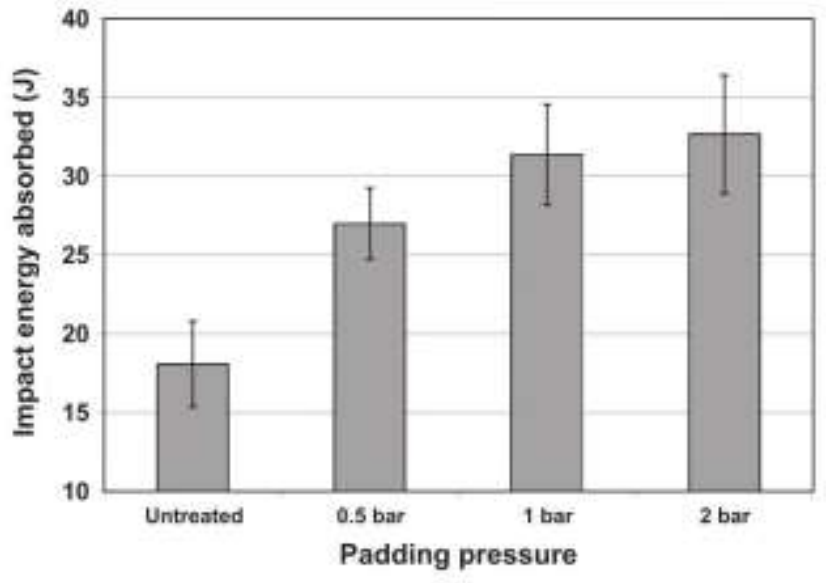

Fig. 9 Padding pressure effect to energy absorption of STF impregnated Kevlar [36]

\section{E. Fabric Architecture}

Other factors affecting stab impact resistance of STF impregnated fabric is fabric weaving architecture. Laha and Majumdar [37] tested five weaving fabric types; plain, 3/1 twill, 2/2 twill, 5 end satin and 2/2 matt with drop weight test. Each five weaving types were woven with different thread densities and impregnated with $60 \%$ weight fraction of STF concentration. They found that STF improved the energy absorbed during impact for each five weaving types, which the highest energy absorption shown in plain type with $30 \times 30$ thread density as illustrated in Fig. 10.

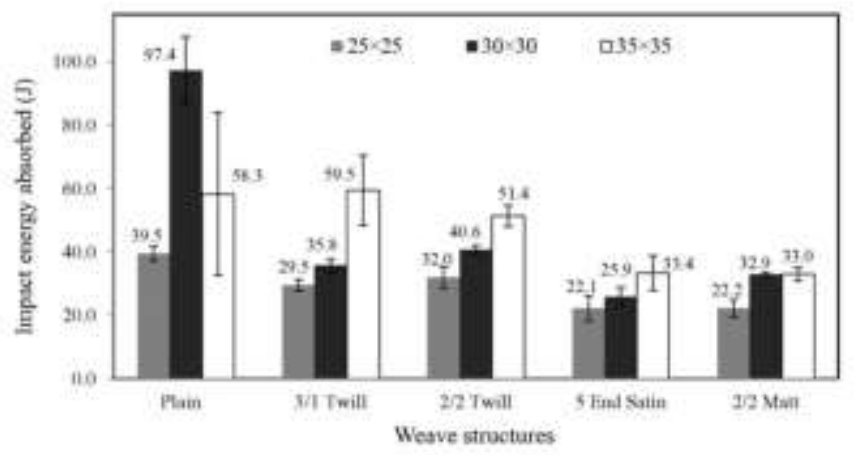

Fig. 10 Impact energy absorption by different weaving fabrics treated with STF [37]

\section{FABRIC DAMAGE MECHANISM}

STF enhance the stab and spike resistance of fabric with their unique behaviour. In spike or puncture threat, STF impregnated fabrics show a remarkable improvement compare to stab threat. During spike event, sharp tip will go through the fabric weaving construction, creating the windowing effects on the fabrics [6]. Windowing effect will pull out the contact yarn as shown in Fig. 11(a). On other hand, STF impregnated fabric does not demonstrated yarn pull out on the samples as Fig. 11(b). STF increase the yarn to yarn friction, making the energy required for penetration become higher than neat fabric. Yarn to yarn friction also improve the load transfer to adjacent yarn making better energy dissipation by forming a cone shape rather than only primary yarn involves in energy dissipation for neat fabric [38], [39].
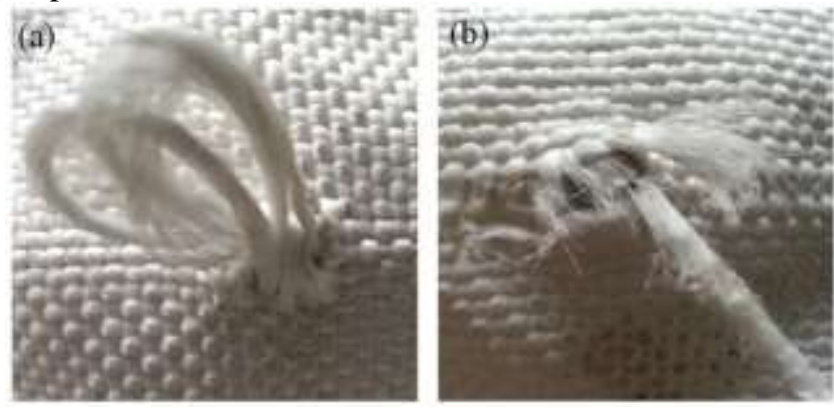

Fig. 11 (a) neat fabric and (b) STF-fabric after testing [26]

Stab threat such as knife has long cutting edge that able to continuous cutting the fabrics during stab [5]. Knife penetration mainly caused by filaments separation with small fibre fracture while STF impregnated fabric shows clean cut with significant fibre fracture as shown in Fig. 12. Neat fabric fractures show irregularity with some filaments are pull out, while STF fabric show regular fracture due to high yarn to yarn friction in fabrics [34].
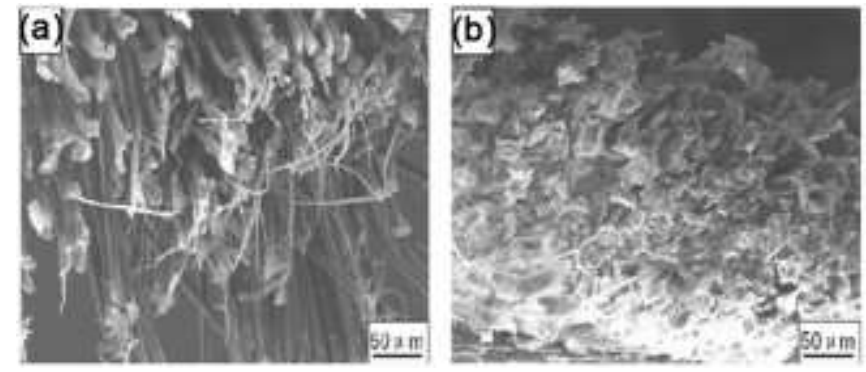

Fig. 12 SEM images of damaged fibre by knife impactor from (a) neat fabric and (b) STF impregnated fabric [34]

\section{CONCLUSION}

A detailed review on stab and spike resistance performance of STF impregnated fabric has been discussed in this paper. STF impregnated fabric demonstrated a superior stab and spike resistance than neat fabric. The improvement of performance for STF-fabrics mainly influenced by the rheological properties of STF. The main energy absorption mechanisms of STF-fabrics is due to enhancement of yarn to yarn friction, which reduce the yarn slippage or pull out for better energy transfer from primary yarns to secondary yarns (adjacent yarns). In conventional soft body armours design, thick layers of fabric were used to encounter stab and spike threats. Therefore, the implementation of STF can reduce the number of fabric layers in the soft body armour while maintaining the stab resistance.

\section{ACKNOWLEDGMENT}

This work is supported by Ministry of Science Technology and Innovation (MOSTI) Malaysia and Universiti Teknologi Malaysia (UTM) through Sciencefund (SF) Vot No. 4S136. 


\section{REFERENCES}

E. Liden, R. Berlin, B. Janzon, B. Schantz, and T. Seeman, "Some observations relating to behind-body armour blunt trauma effects caused by ballistic impact," J. Trauma, vol. 28, no. 1, pp. S145S148, 1988

[2] National Institute of Justice, "Ballistic Resistance of Personal Body Armor," NIJ Stand., 2000.

[3] L. Wang, S. Kanesalingam, R. Nayak, and R. Padhye, "Recent Trends in Ballistic Protection," Text. Light Ind. Sci. Technol., vol. 3 , no. 0 , p. 37, 2014.

[4] National Institute of Justice, "Stab Resistance of Personal Body Armor," 2000

[5] M. El Messiry and E. Eltahan, "Stab resistance of triaxial woven fabrics for soft body armor," J. Ind. Text., vol. 45, no. 5, pp. 1062 1082, 2014.

[6] M. Cemal Kuşhan, S. Gürgen, T. Ünalir, and S. Çevik, "a Novel Approach for Armor Applications of Shear Thickening Fluids in Aviation and Defense Industry," 2014.

[7] E. D. Wetzel, "The Effect of Rheological Parameters on the Ballistic Properties of Shear Thickening Fluid (STF)-Kevlar Composites," AIP Conf. Proc., vol. 712, no. May 2013, pp. 288293, 2004

[8] Y. Park, Y. Kim, A. H. Baluch, and C. Kim, "Empirical study of the high velocity impact energy absorption characteristics of shear thickening fluid (STF) impregnated Kevlar fabric," Int. J. Impact Eng., vol. 72, pp. 67-74, 2014.

[9] T. A. Hassan, V. K. Rangari, and S. Jeelani, "Synthesis, processing and characterization of shear thickening fluid (STF) impregnated fabric composites," Mater. Sci. Eng. A, vol. 527, no. 12, pp. 2892 2899, 2010

[10] E. D. Wetzel, P. N. J. Wagner, and Y. S. Lee, "Novel Flexible Body Armor Utilizing Shear Thickening Fluid ( STF ) Composites," Chem. Eng., no. July 2003, pp. 1-19, 2003.

[11] V. K. Rangari, T. A. Hassan, H. Mahfuz, and S. Jeelani, "Synthesis of Shear Thickening Fluid Using Sonochemical Method," vol. 2, pp. 637-640, 2006.

[12] V. B. C. Tan, T. E. Tay, and W. K. Teo, "Strengthening fabric armour with silica colloidal suspensions," Int. J. Solids Struct., vol, 42, no. 5-6, pp. 1561-1576, 2005.

[13] N. C. Crawford, L. B. Popp, K. E. Johns, L. M. Caire, B. N. Peterson, and M. W. Liberatore, "Shear thickening of corn starch suspensions: Does concentration matter?," J. Colloid Interface Sci., vol. 396, pp. 83-89, 2013.

[14] M. Fahool and A. R. Sabet, "UV-visible assessment of hydrocluster formation and rheological behaviour in bimodal and mono-disperse shear thickening fluids," Rheol. Acta, vol. 54, no. 1, pp. 77-83, 2015.

[15] R. L. Hoffman, "Explanations for the cause of shear thickening in concentrated colloidal suspensions," J. Rheol. (N. Y. N. Y)., vol. 42, no. 1 , p. $111,1998$.

[16] J. W. Bender and Norman J. Wagner, "Optical Measurement of the Contributions of Colloidal Forces to the Rheology of Concentrated Suspensions," Journal of Colloid and Interface Science, vol. 172, no. 1. p. 171, 1995.

[17] B. J. Maranzano and N. J. Wagner, "Flow-small angle neutron scattering measurements of colloidal dispersion microstructure evolution through the shear thickening transition," J. Chem. Phys., vol. 117, no. 22, pp. 10291-10302, 2002.

[18] E. Brown, N. a Forman, C. S. Orellana, H. Zhang, B. W. Maynor, D. E. Betts, J. M. DeSimone, and H. M. Jaeger, "Generality of shear thickening in dense suspensions.," Nat. Mater., vol. 9, no. 3, pp. 220-224, 2010.

[19] C. Sauter, M. A. Emin, H. P. Schuchmann, and S. Tavman, "Influence of hydrostatic pressure and sound amplitude on the ultrasound induced dispersion and de-agglomeration of nanoparticles," Ultrason. Sonochem., vol. 15, no. 4, pp. 517-523, 2008.

[20] T. A. Hassan, V. K. Rangari, and S. Jeelani, "Sonochemical synthesis and rheological properties of shear thickening silica dispersions," Ultrason. Sonochem., vol. 17, no. 5, pp. 947-952, 2010 .
[21] X. Z. Zhang, W. H. Li, and X. L. Gong, "The rheology of shear thickening fluid (STF) and the dynamic performance of an STFfilled damper," Smart Mater. Struct., vol. 17, no. 3, p. 35027, 2008

[22] N. Kordani and A. S. Vanini, "Optimizing the ethanol content of shear thickening fluid/fabric composites under impact loading," $J$. Mech. Sci. Technol., vol. 28, no. 2, pp. 663-667, 2014.

[23] A. Haris, H. P. Lee, T. E. Tay, and V. B. C. Tan, "Shear thickening fluid impregnated ballistic fabric composites for shock wave mitigation," Int. J. Impact Eng., vol. 80, pp. 143-151, 2015.

[24] M. Fahool and A. R. Sabet, "Parametric study of energy absorption mechanism in Twaron fabric impregnated with a shear thickening fluid," Int. J. Impact Eng., vol. 90, pp. 61-71, 2016.

[25] Y. Xu, X. Chen, Y. Wang, and Z. Yuan, "Stabbing resistance of body armour panels impregnated with shear thickening fluid," Compos. Struct., vol. 163, pp. 465-473, 2017.

[26] M. Hasanzadeh, V. Mottaghitalab, H. Babaei, and M. Rezaei, "The influence of carbon nanotubes on quasi-static puncture resistance and yarn pull-out behavior of shear-thickening fluids (STFs) impregnated woven fabrics," Compos. Part A Appl. Sci. Manuf., vol. 88, pp. 263-271, 2016.

[27] E. Balali, N. Kordani, and A. Sadough Vanini, "Response of glass fiber-reinforced hybrid shear thickening fluid (STF) under lowvelocity impact," J. Text. Inst., vol. 5000, no. November, pp. 1-11, 2016

[28] Y. S. Lee, E. D. Wetzel, and N. J. Wagner, "The ballistic impact characteristics of Kevlar woven fabrics impregnated with a colloidal shear thickening fluid," J. Mater. Sci., vol. 38, no. 13, pp. 28252833, 2003

[29] S. H. A. Afeshejani, S. A. R. Sabet, M. E. Zeynali, and M. Atai, "Energy Absorption in a Shear-Thickening Fluid," J. Mater. Eng. Perform., vol. 23, no. 12, pp. 4289-4297, 2014.

[30] K. Yu, H. Cao, K. Qian, L. Jiang, and H. Li, "Synthesis and stab resistance of shear thickening fluid (STF) impregnated glass fabric composites," Fibres Text. East. Eur., vol. 95, no. 6, pp. 126-128, 2012

[31] P. Ternik, J. Marn, and Z. Žunič, "Non-Newtonian fluid flow through a planar symmetric expansion: Shear-thickening fluids," $J$. Nonnewton. Fluid Mech., vol. 135, no. 2-3, pp. 136-148, 2006.

[32] B.-W. Lee, I.-J. Kim, and C.-G. Kim, "The Influence of the Particle Size of Silica on the Ballistic Performance of Fabrics Impregnated with Silica Colloidal Suspension," J. Compos. Mater., vol. 43, no. 23, pp. 2679-2698, 2009.

[33] B. J. Maranzano and N. J. Wagner, "The effects of particle size on reversible shear thickening of concentrated colloidal dispersions," $J$. Chem. Phys., vol. 114, no. 23, p. 10514, 2001.

[34] X. Feng, S. Li, Y. Wang, Y. Wang, and J. Liu, "Effects of different silica particles on quasi-static stab resistant properties of fabrics impregnated with shear thickening fluids," Mater. Des., vol. 64, pp. 456-461, 2014

[35] H. a. Barnes, "Shear-Thickening ('Dilatancy') in Suspensions of Nonaggregating Solid Particles Dispersed in Newtonian Liquids," $J$. Rheol. (N. Y. N. Y)., vol. 33, no. 2, p. 329, 1999.

[36] A. Majumdar, B. S. Butola, and A. Srivastava, "Development of soft composite materials with improved impact resistance using Kevlar fabric and nano-silica based shear thickening fluid," Mater. Des., vol. 54, pp. 295-300, 2014.

[37] A. Laha and A. Majumdar, "Interactive effects of p-aramid fabric structure and shear thickening fluid on impact resistance performance of soft armor materials," Mater. Des., vol. 89, pp. 286-293, 2016

[38] M. Hasanzadeh and V. Mottaghitalab, "The role of shear-thickening fluids (STFs) in ballistic and stab-resistance improvement of flexible armor," J. Mater. Eng. Perform., vol. 23, no. 4, pp. 11821196, 2014.

[39] J. Ding, P. Tracey, W. Li, G. Peng, P. G. Whitten, and G. G. Wallace, "Review on Shear Thickening Fluids and Applications," Text. Light Ind. Sci. Technol., vol. 2, no. 4, pp. 161-173, 2013. 